\title{
Role of Somatostatin Analogues in the Treatment of Neuroendocrine Tumors
}

\author{
Sujata Narayanan, MD, MS, and Pamela L. Kunz, MD
}

\begin{abstract}
Neuroendocrine tumors (NETs) are rare epithelial neoplasms with neuroendocrine differentiation that most commonly originate in the lungs and gastrointestinal tract. Many patients have advanced disease not amenable to surgery or local management. Some tumors also secrete amines, such as serotonin, that lead to syndromes of hormone excess, such as diarrhea and flushing. Thus, management of patients with NETs often requires a dual approach, including hormone symptom management and systemic tumor control. Somatostatin analogues have long been a mainstay of managing the hormone-related symptoms, and increasing evidence also supports their use for tumor control in patients with well-differentiated NETs. This article reviews the role of somatostatin analogues in the treatment of NETs. (J Natl Compr Canc Netw 2015;13:109-117)
\end{abstract}

\section{NCCN: Continuing Education}

\section{Accreditation Statement}

This activity has been designated to meet the educational needs of physicians and nurses involved in the management of patients with cancer. There is no fee for this article. No commercial support was received for this article. The National Comprehensive Cancer Network (NCCN) is accredited by the ACCME to provide continuing medical education for physicians.

From Stanford University School of Medicine, Stanford, California

Submitted September 22, 2014; accepted for publication December 15, 2014.

Dr. Narayanan has disclosed that she has no financial interests, arrangements, affiliations, or commercial interests with the manufacturers of any products discussed in this article or their competitors. Dr. Kunz receives research support from Genentech, Inc.; Merck \& Co., Inc.; Novartis Pharmaceuticals Corporation; Advanced Accelerator Applications; and Lexicon Pharmaceuticals, Inc.; and serves on an advisory board for Guardant Health, Novartis Pharmaceuticals Corporation, and Ipsen Biopharmaceuticals, Inc.; and holds stock in Guardant Health.

Correspondence: Pamela L. Kunz, MD, Stanford Cancer Center, 875 Blake Wilbur Drive Stanford, CA 94305-5826. E-mail: pkunz@stanford.edu
NCCN designates this journal-based CME activity for a maximum of 1.0 AMA PRA Category 1 Credit(s) TM. Physicians should claim only the credit commensurate with the extent of their participation in the activity.

NCCN is accredited as a provider of continuing nursing education by the American Nurses Credentialing Center's Commission on Accreditation.

This activity is accredited for 1.0 contact hour. Accreditation as a provider refers to recognition of educational activities only; accredited status does not imply endorsement by NCCN or ANCC of any commercial products discussed/displayed in conjunction with the educational activity. Kristina M. Gregory, RN, MSN, OCN, is our nurse planner for this educational activity.

All clinicians completing this activity will be issued a certificate of participation. To participate in this journal CE activity: 1) review the learning objectives and author disclosures; 2 ) study the education content; 3) take the posttest with a $66 \%$ minimum passing score and complete the evaluation at http://education.nccn.org/ node/59437; and 4) view/print certificate.

Release date: January 1, 2015; Expiration date: January 1, 2016

\section{Learning Objectives}

Upon completion of this activity, participants will be able to:

- Explain some of the clinical approaches available to manage patients with NETs

- Summarize the role of somatostatin analogues in the treatment of NETs

EDITOR

Kerrin M. Green, MA, Assistant Managing Editor, JNCCN—Journal of the National Comprehensive Cancer Network

Ms. Green has disclosed that she has no relevant financial relationships.

\section{CE AUTHORS}

Deborah J. Moonan, RN, BSN, Director, Continuing Education, has disclosed that she has no relevant financial relationships.

Ann Gianola, MA, Manager, Continuing Education Accreditation \& Program Operations, has disclosed that she has no relevant financial relationships.

Kristina M. Gregory, RN, MSN, OCN, Vice President, Clinical Information Operations, has disclosed that she has no relevant financial relationships. Rashmi Kumar, PhD, Senior Manager, Clinical Content, has disclosed that she has no relevant financial relationships.

Deborah A. Freedman-Cass, PhD, Oncology Scientist/Senior Medical Writer, has disclosed that she has no relevant financial relationships. Ms. Gregory has disclosed that she has no relevant financial relationships. 
Neuroendocrine tumors (NETs) are epithelial neoplasms with neuroendocrine differentiation that arise in various anatomic locations throughout the body. Although most NETs are sporadic, they can be also part of familial syndromes, such as multiple endocrine neoplasia types 1 and 2. The annual incidence of NETs in the United States is approximately 3.65 per 100,000 persons and recent analyses have indicated an increase in the incidence of carcinoid tumors in the United States and elsewhere, ${ }^{1-4}$ partly because of their increased detection on radiographic imaging and endoscopy. NETs are often classified by their organ of origin (eg, lung, pancreas, gastrointestinal tract) and their secretion of various peptides and neuroamines. Those that actively secrete hormones and cause clinical symptoms are referred to as functional. Carcinoid syndrome is the characteristic syndrome of hormone excess occurring in functional NETs that secrete vasoactive substances such as serotonin, and is associated with diarrhea and flushing. Nonfunctional NETs have no specific clinical syndrome but may still secrete peptides or neuroamines, measurable in plasma or urine.

The most recent WHO classification of neuroendocrine neoplasms of the digestive system in $2010^{5}$ separated NETs into well-differentiated, low-grade (G1); well-differentiated, intermediate-grade (G2); and poorly differentiated, high-grade neuroendocrine carcinomas (G3), incorporating clinical, molecular, and histopathologic features of these tumors, and specifically recognizing the biologic behavior according to location and degree of tumor differentiation. The survival rates from these tumors also vary according to primary site and grade, and are considerably lower in patients with poorly differentiated neuroendocrine carcinomas than in those with well-differentiated NETs. Patients with localized disease have a better prognosis than those with distant metastatic disease. ${ }^{2}$

For localized tumors, surgical resection is the mainstay of treatment. Nonsurgical options, such as liver-directed therapies and systemic therapy with molecularly targeted agents, cytotoxic chemotherapy, and somatostatin analogues, play a key role in the management of unresectable metastatic tumors, with the goal of alleviating symptoms of peptide release and shrinking the tumor mass. Somatostatin analogues have long been used to control symptoms of hormonal excess in patients with NETs, and only recently have been appreciated as antiproliferative agents for patients with well-differentiated metastatic disease. This article reviews the role of somatostatin analogues in the treatment of well-differentiated NETs.

\section{Physiology of Somatostatin and Somatostatin Receptors}

The somatostatin neuropeptide family includes 2 bioactive proteins: the predominant but functionally less active SST14, and a larger more potent molecular form, SST28. ${ }^{6}$ The somatostatins have a very short circulation half-life $(\approx 2$ minutes $),{ }^{7}$ and thus the somatostatin-producing cells are located close to its target cells. ${ }^{8}$ Both SST14 and SST28 act in an autocrine, paracrine, or neuronal regulatory manner, inhibiting glandular secretion, neurotransmission, smooth-muscle contractility, and absorption of nutrients. Somatostatin mediates its primarily inhibitory effects by binding to at least 5 high-affinity Gprotein-coupled membrane receptors (SSTR1-5). ${ }^{9}$ The somatostatin receptors share approximately $40 \%$ to $60 \%$ homology, but mediate different biological actions on activation. ${ }^{10}$ All 5 somatostatin receptors have been identified throughout the central nervous system and gastrointestinal tract, in the endocrine and exocrine glands, and on inflammatory and immune cells. Tumors arising from somatostatin-target tissues, such as the pancreas and small intestine, express a high density of somatostatin receptors. ${ }^{11-13}$ SSTR2 predominance is seen in most pancreatic and gastrointestinal-tract NETs.

The physiologic effects of somatostatin are largely inhibitory; it reduces gastrointestinal motility and gallbladder contraction; inhibits secretion of most gastrointestinal hormones, insulin, glucagon, and gastrin; reduces blood flow in the gastrointestinal tract; and inhibits growth hormone release from the pituitary gland and neurotransmission in the brain. ${ }^{14,15}$ Given this inhibitory profile of somatostatin, its activity has been used clinically for various indications, including the treatment of acromegaly, secretory diarrhea, and gastrointestinal bleeding; inhibition of tumor growth; treatment for symptoms of NET hormone excess; and imaging of neuroendocrine and other solid tumors.

Somatostatin was first used to control symptoms caused by NETs in the 1970 s. ${ }^{16,17}$ However, given its 
short half-life requiring a cumbersome continuous infusion and rebound hypersecretion of hormones, its routine clinical application was limited. These properties of somatostatin resulted in the development of synthetic analogues beginning in the early 1980s, including octreotide and lanreotide, and, more recently, pasireotide. These peptides are more resistant to degradation, and their half-lives, and hence their biological activities, are substantially longer than those of native somatostatin (1.5-2 hours vs $1-2$ minutes). ${ }^{18}$ They vary in their affinity toward different somatostatin receptor subtypes, ${ }^{10,19}$ and bind mainly to SSTR2, and much less to SSTR5. The newly developed somatostatin analogue pasireotide is a new "universal" or "pan-receptor" somatostatin analogue, having a high affinity for SSTR1, SSTR2, SSTR3, and SSTR5 subtypes. ${ }^{20}$ Table 1 lists the affinity of somatostatin and synthetic somatostatin analogues to the somatostatin receptor subtypes. ${ }^{20-22}$

\section{Somatostatin Analogues for Control of Hormone Release}

\section{Treating Symptoms of Hormone Excess}

Octreotide was the first somatostatin analogue developed for clinical application, with 3 times more potency than naturally occurring somatostatin and a more practical half-life of 2 hours; it shows a high affinity toward SSTR2 and SSTR5. The short-acting formulation of octreotide can be given via continuous infusion or as a subcutaneous injection 2 to 3 times per day; it is not associated with the side effects of rebound hormonal hypersecretion. Longer-acting formulations were developed to provide more sustained drug levels, of which octreotide long-acting release (LAR) was the first in the 1990s. Octreotide LAR is administered at 20 to $30 \mathrm{mg}$ as a monthly intramuscular injection. Continuing initial shortacting formulation coverage for approximately 2 to 3 weeks is generally recommended until steady-state levels of octreotide LAR are achieved. Studies comparing the shorter-acting and longer-acting forms of octreotide have demonstrated equal efficacy in terms of symptom control, with symptomatic response rates of $60 \%$ to $72 \%$ across groups. ${ }^{23}$

Lanreotide is another somatostatin analogue with similar somatostatin receptor-binding affinity as octreotide. Lanreotide has 2 formulations currently available: sustained-release lanreotide, given as an intramuscular injection every 2 weeks, and prolonged-release lanreotide, given as deep subcutaneous injections every 4 weeks. Lanreotide is approved both in Europe and the United States for treatment of acromegaly. Lanreotide has demonstrated symptom improvement in patients with carcinoid syndrome in several small prospective and retrospective studies. ${ }^{24-26}$ Short-acting octreotide and sustainedrelease lanreotide were shown to be equally effective in controlling carcinoid syndrome. ${ }^{27}$ Additionally, in

\begin{tabular}{|c|c|c|c|c|c|}
\hline & \multicolumn{5}{|c|}{ Affinity to Somatostatin Receptors, $\mathrm{IC}_{50}(\mathrm{nmol})$} \\
\hline & SSTR1 & SSTR2 & SSTR3 & SSTR4 & SSTR5 \\
\hline \multicolumn{6}{|l|}{ Native somatostatin } \\
\hline SST28 & 5.2 & 2.7 & 7.7 & 5.6 & 4.0 \\
\hline \multicolumn{6}{|l|}{ Synthetic somatostatin analogues } \\
\hline Octreotide & $>10,000$ & 2.0 & 187 & $>1,000$ & 22 \\
\hline Lanreotide & 180 & 0.54 & 14 & 230 & 17 \\
\hline Pasireotide & 9.3 & 1 & 1.5 & $>100$ & 0.16 \\
\hline \multicolumn{6}{|l|}{ Radiopeptides } \\
\hline$\left[{ }^{90} \mathrm{Y}\right.$-DOTA $\left.{ }^{0}, \mathrm{Tyr}^{3}\right]$ octreotide $\left({ }^{90} \mathrm{Y}\right.$-DOTATOC) & $>10,000$ & 11 & 389 & $>10,000$ & 114 \\
\hline${ }^{90}$ Y-DOTA-lanreotide (DOTALAN) & $>10,000$ & 23 & 290 & $>10,000$ & 16 \\
\hline$\left[{ }^{90} \mathrm{Y}-\mathrm{DOTA}{ }^{0}, \mathrm{Tyr}^{3}\right]$ octreotate (DOTATATE) & $>10,000$ & 1.6 & $>1000$ & 523 & 187 \\
\hline [90Y-DOTA]-1-Nal ${ }^{3}$-octreotide (DOTA-NOC) & $>1000$ & 3.3 & 26 & $>1000$ & 10 \\
\hline
\end{tabular}

Abbreviations: $I_{50^{\prime}}$ Inhibitory concentration (half maximal); $Y$, yttrium. Data from references 20-22. 
a recent phase III study of lanreotide versus placebo in patients who were somatostatin analogue-naïve or responsive to conventional doses of octreotide, lanreotide reduced the need for short-acting octreotide ( $49 \%$ vs $34 \%$; absolute difference $15 \% ; P=.02$ ); however, the results did not meet the predefined $a b$ solute difference of $30 \% .28$

Pasireotide was developed as an agent with a broader somatostatin receptor profile similar to that of natural somatostatin. It binds with high affinity to somatostatin receptor subtypes SSTR1, SSTR2, SSTR3, and SSTR5 and displays a 30- to 40-fold higher affinity for SSTR1 and SSTR5 than octreotide or lanreotide. ${ }^{20}$ Given its greater binding affinity, hypotheses have proposed that it may have a greater inhibitory effect than octreotide on hormones secreted by carcinoid tumors. ${ }^{29}$ A multicenter, randomized, blinded phase III study of pasireotide LAR versus octreotide LAR in patients with symptomatic metastatic NETs showed that these drugs had equal efficacy in controlling symptoms of hormone secretion. ${ }^{30}$ The safety profile was similar, except regarding hyperglycemia, which was higher in the pasireotide arm (11\% vs 0\%).

Lastly, it has historically been recommended that patients with functional NETs receive prophylactic periprocedural intravenous octreotide to prevent carcinoid crisis. Carcinoid crisis is thought to be a syndrome of sudden-onset severe carcinoid syndrome and vasomotor collapse. However, the physiology is poorly understood, and it is unclear which patients with NET are at risk for carcinoid crisis, and may include those with classic carcinoid syndrome and those with nonfunctional tumors.

Massimino et $\mathrm{al}^{31}$ recently reported a singleinstitution retrospective experience of 97 patients with carcinoid tumors undergoing surgery. This study found that octreotide LAR and bolus octreotide are insufficient in preventing intraoperative complications. Future definitive studies are needed to better understand carcinoid crisis and develop preventive strategies.

\section{Dosing for Hormone-Related Symptoms}

When somatostatin analogues are used for symptom control, the recommendation is to start short-acting somatostatin analogues immediately in an effort to provide immediate symptom relief, and then overlap them with long-acting somatostatin analogues until steady-state levels are reached $\left(\approx 2\right.$ weeks). ${ }^{32}$ The sug- gested starting dose of octreotide acetate ranges from 100 to $600 \mathrm{mcg} / \mathrm{d}$ in 2 to 4 divided doses; test doses are not routinely required. Doses are usually initiated at the lower dose range and can be individually titrated to control symptoms; some patients may require significantly higher doses (up to $1.5 \mathrm{mg} / \mathrm{d}$ ).

The recommended dose of octreotide LAR is 20 to $30 \mathrm{mg}$ via deep intramuscular injection repeated every 4 weeks. Correct intramuscular injection can be challenging. One report noted that only $52 \%$ of injections were successfully delivered and that correct intramuscular injection was associated with improved control of flushing among patients with carcinoid syndrome. ${ }^{33}$ Some patients also require "rescue" doses of short-acting octreotide to control breakthrough symptoms even after initiation of the long-acting formulation; these commonly occur in the days preceding a scheduled octreotide injection. Dose and frequency of both short- and long-acting somatostatin analogues may be further increased for symptom control as needed. ${ }^{34}$

Two controversial topics in somatostatin analogue dosing include the role of plasma octreotide levels and the risk of tachyphylaxis. Data showing a benefit associated with plasma octreotide monitoring are lacking, and therefore routine use is not recommended. Additionally, risk of tachyphylaxis after long-term use of somatostatin analogues has been postulated, although the mechanism of tachyphylaxis is poorly understood and rigorous prospective data are lacking.

Lastly, the dosing of somatostatin analogues in elderly patients with carcinoid syndrome requires special mention. Most patients with NETs are diagnosed in their seventh decade, with a median age of 63 years. $^{2}$ In a recent study of the SEER-Medicare databases, Shen et $\mathrm{al}^{35}$ showed that only $50 \%$ of elderly patients with FDA-approved indications (carcinoid syndrome or metastatic disease) started octreotide LAR within 6 months of diagnosis, and that octreotide LAR use was lowest among patients aged 80 years and older. However, they also showed that the use of octreotide LAR within 6 months of diagnosis of carcinoid syndrome was associated with better survival for patients with metastatic disease. This study suggests that somatostatin analogue use in elderly patients with functional NETs may be underused and should be addressed in future studies. 


\section{Somatostatin Analogues for Control of Tumor Growth}

\section{Treatment for Control of Tumor Growth}

Somatostatin analogues have also demonstrated antiproliferative properties in NETs, with varying effects depending on the primary site and somatostatin receptor subtype. For example, SSTR2 and SSTR5 have been shown to mediate the antimitotic activity, leading to cell cycle arrest. ${ }^{36}$ Somatostatin analogues may also exert an indirect antiproliferative effect by inhibiting the release of growth factors and various trophic hormones, such as growth hormone, insulin-like growth factor-1, insulin, gastrin, and epidermal growth factor, both from the neoplastic cell and from the surrounding tumour matrix..$^{37}$ Somatostatin analogues have also been postulated to reduce the vascularization of the neoplastic tissue in experimental models via inhibition of vascular endothelial growth factor. ${ }^{38}$

The first clinical trial to demonstrate prolonged time to tumor progression (TTP) with somatostatin analogues in NETs was the PROMID study. ${ }^{39}$ In this phase III randomized, double-blind, placebocontrolled, multi-institutional German study, 85 patients with well-differentiated metastatic midgut NETs were randomized to receive $30 \mathrm{mg}$ of octreotide LAR monthly via intramuscular injection versus placebo. Octreotide significantly improved TTP compared with placebo (14.3 vs 6.0 months in the placebo arm; hazard ratio $[\mathrm{HR}]=0.34 ; 95 \%$ CI, 0.20-0.59; $P=.000072$ ); median overall survival (OS) could not be calculated at the time of initial analysis. The study also found that functionally active and inactive tumors responded similarly, and the most favorable effect was observed in patients with low hepatic tumor volume and resected primary tumors. Updated OS data were presented in 2013; median OS was not reached in the octreotide LAR arm compared with 84 months in the placebo arm (HR, 0.85; CI, 0.46-1.56; $P=.59$ ). A survival benefit was seen for patients receiving octreotide LAR with low hepatic tumor volume ( $<10 \%$ liver involvement) but not for patients with high hepatic tumor volume $(>10 \%)$. Although this study did not formally impact the FDA label for octreotide LAR, octreotide was widely adopted for controlling tumor growth in patients with metastatic midgut NETs.

The CLARINET study was a phase III randomized, double-blind, placebo-controlled, multina- tional study of lanreotide in patients with advanced, well- or moderately differentiated, nonfunctioning, somatostatin receptor-positive NETs of grade 1 or 2 (with a $\mathrm{Ki}-67$ antigen level of $<10 \%$ ). Patients were randomized to receive $120 \mathrm{mg}$ of lanreotide via deep subcutaneous injection every 28 days versus placebo. In 205 enrolled patients, lanreotide significantly improved progression-free survival compared with placebo (18.0 months vs median not reached; HR, 0.47; 95\% CI, 0.30-0.73; P<.001). No difference was seen in median OS. In an open-label extension study, 88 patients from the CLARINET core study continued on lanreotide ( 41 from the lanreotide arm and 47 from the placebo arm). Of the subset of patients who experienced disease progression while on placebo in the core study, median time to further progression was 14 months. ${ }^{40}$

The PROMID and CLARINET studies are both important to the field of NETs because they demonstrate the antiproliferative effect of somatostatin analogues. Some key differences between these studies are worth highlighting (Table 2). Most notably, PROMID included patients with small bowel NETs, grade 1 tumors, low hepatic tumor volume, and a relatively short interval from diagnosis. CLARINET included a broader patient population with a predominance of pancreas and small bowel primary sites, both grade 1 and 2 tumors, higher hepatic tumor volume, mostly patients with stable disease during a 3- to 6-month prestudy observation period, and

\begin{tabular}{|c|c|c|}
\hline Characteristic & PROMID & CLARINET \\
\hline $\mathrm{N}$ & 85 & 204 \\
\hline Primary site & Midgut only & $\begin{array}{l}\text { Pancreas }(45 \%) \\
\text { Midgut }(35 \%) \\
\text { Hindgut }(7 \%) \\
\text { Unknown primary/ } \\
\text { other }(13 \%)\end{array}$ \\
\hline Tumor grade & $1(\mathrm{Ki} 67 \leq 2 \%)$ & 1 and $2(\mathrm{Ki} 67<10 \%)$ \\
\hline $\begin{array}{l}\text { Hepatic tumor } \\
\text { volume }\end{array}$ & $\begin{array}{l}0 \%-10 \% \text { volume }(75 \%) \\
10 \%-25 \% \text { volume }(6 \%) \\
>25 \% \text { volume }(19 \%)\end{array}$ & $\begin{array}{l}\leq 25 \% \text { volume }(67 \%) \\
>25 \% \text { volume }(33 \%)\end{array}$ \\
\hline $\begin{array}{l}\text { Tumor } \\
\text { progression at } \\
\text { baseline }\end{array}$ & Unknown & $4 \%$ \\
\hline $\begin{array}{l}\text { Time from } \\
\text { diagnosis }\end{array}$ & $\begin{array}{l}\text { Octreotide: } 7.5 \mathrm{mo} \\
\text { Placebo: } 3.3 \mathrm{mo}\end{array}$ & $\begin{array}{l}\text { Lanreotide: } 13.2 \mathrm{mo} \\
\text { Placebo: } 16.5 \mathrm{mo}\end{array}$ \\
\hline $\begin{array}{l}\text { Tumor } \\
\text { response } \\
\text { assessment } \\
\text { tool }\end{array}$ & WHO & RECIST \\
\hline
\end{tabular}


a longer median time from diagnosis. CLARINET contributes new information to the field, because it demonstrates the activity of somatostatin analogues in non-midgut tumors with higher grade and higher hepatic tumor volume, and raises the question whether somatostatin analogues should be used in patients with stable disease. However, the 18-month median progression-free survival in the placebo arm is encouraging and may also argue that active surveillance in select patients is reasonable. The CLARINET study has not demonstrated an OS difference, which could be attributed to crossover, need for longer follow-up, and perhaps a more indolent disease, as evidenced by a longer time from diagnosis compared with PROMID. Other completed and ongoing clinical trials evaluating somatostatin analogues for control of tumor growth in NETs are summarized in Tables 3 and 4 .

\section{Dosing for Control of Tumor Growth}

Octreotide LAR, $30 \mathrm{mg}$ via intramuscular injection monthly, and lanreotide, $120 \mathrm{mg}$ via a deep subcutaneous injection are standard somatostatin analogue doses used for tumor control based on the PROMID and CLARINET studies, respectively. In contrast to dosing for hormone control, a 2-week overlap with short-acting octreotide is not required. Few high-level data support the routine use of below- or above-standard doses of somatostatin analogues for tumor control.

\section{Somatostatin Analogue Side Effects}

The most commonly encountered side effects of somatostatin analogues include nausea, abdominal cramps, diarrhea, steatorrhea, flatulence, hyperglycemia, and cholelithiasis/biliary sludging. Most of these symptoms are dose-dependent and resolve within the first few weeks of treatment. Cholelithiasis and/or gallbladder sludge occurs secondary to the inhibition of gallbladder contraction and emptying, and can develop in approximately $50 \%$ of patients on somatostatin analogues. Although this side effect is also dose-dependent, only $1 \%$ of patients develop acute symptoms requiring cholecystectomy. ${ }^{41}$ It has been recommended that cholecystectomy be performed prophylactically in patients with NETs who are undergoing or considering somatostatin analogue therapy. ${ }^{32}$ Local discomfort may also be experienced for all methods of administration (subcutaneous, deep subcutaneous, intramuscular injection). In patients with insulinomas, somatostatin analogues should be used with caution because they have the potential to worsen hypoglycemia by suppressing glucagon secretion.

\section{Radiolabelled Somatostatin Analogues in NET Therapeutics}

Peptide receptor radionuclide therapy (PRRT) with radiolabelled somatostatin analogues is a relatively new and promising treatment modality for patients with inoperable or metastatic NETs. This treatment is based on the same principle used in somatostatin receptor scintigraphy, such as indium-111 ( $\left.{ }^{111} \mathrm{In}\right)$ labeled octreotide scintigraphy (OctreoScan) and the newer galium-68 ( $\left.{ }^{68} \mathrm{G}\right)$-labeled DOTA PET scans. The radiolabeled somatostatin analogues

\section{Table 3 Summary of Completed Randomized Clinical Trials With Somatostatin Analogues}

\begin{tabular}{|c|c|c|c|c|c|c|}
\hline Phase & Therapy & $\mathbf{n}$ & Patients & $\begin{array}{l}\text { TTP or PFS } \\
(\mathrm{mo})\end{array}$ & $\begin{array}{l}\text { OS } \\
(\mathrm{mo})\end{array}$ & $\mathbf{R R}$ \\
\hline \multicolumn{7}{|c|}{ Single-agent studies } \\
\hline II (PROMID) & Octreotide vs placebo & 85 & Midgut & 14.3 vs 6.0 & NR & $2 \%$ \\
\hline III (CLARINET) & Lanreotide vs placebo & 204 & $\begin{array}{l}\text { Pancreas, midgut, } \\
\text { hindgut, unknown }\end{array}$ & 18.0 vs NR & NR & NA \\
\hline \multicolumn{7}{|c|}{ Combination studies } \\
\hline III (RADIANT-2) & $\begin{array}{l}\text { Everolimus/octreotide vs } \\
\text { placebo/octreotide }\end{array}$ & 429 & $\begin{array}{l}\text { NETs with carcinoid } \\
\text { syndrome }\end{array}$ & $\begin{array}{l}16.4 \text { vs } \\
11.3 a\end{array}$ & NR & $\begin{array}{l}2 \% \text { vs } \\
2 \%\end{array}$ \\
\hline III (SWOG 0518) & $\begin{array}{l}\text { IFN/octreotide vs } \\
\text { bevacizumab/octreotide }\end{array}$ & 400 & High-risk NETs & \multicolumn{3}{|c|}{$\begin{array}{l}\text { DSMC reported as negative study; } \\
\text { formal data pending }\end{array}$} \\
\hline
\end{tabular}

Abbreviations: DSMC, data safety and monitoring committee; NA, not applicable; NR, not reached; OS, overall survival; PFS, progression-free survival; RR, relative risk; TTP, time to progression.

aNot statistically different. 
Somatostatin Analogues in Treatment of NETs

\begin{tabular}{|c|c|c|c|c|c|c|}
\hline Phase & Therapy & $\mathbf{n}$ & Patients & $\begin{array}{l}\text { Primary End } \\
\text { Point }\end{array}$ & $\begin{array}{l}\text { ClinicalTrials.gov } \\
\text { Identifier }\end{array}$ & Status \\
\hline II (COOPERATE-2) & $\begin{array}{l}\text { Everolimus vs } \\
\text { everolimus/pasireotide }\end{array}$ & 160 & pNET & PFS & NCT01374451 & $\begin{array}{l}\text { Closed to } \\
\text { accrual }\end{array}$ \\
\hline III (NETTER-1) & $\begin{array}{l}{\left[{ }^{177} \mathrm{Lu}^{\left.-D O T A^{0}, \mathrm{Tyr}^{3}\right]-}\right.} \\
\text { octreotate vs high- } \\
\text { dose octreotide }\end{array}$ & 280 & Midgut & PFS & NCT01578239 & Enrolling \\
\hline III (LUNA) & $\begin{array}{l}\text { Pasireotide vs } \\
\text { everolimus vs both }\end{array}$ & 120 & $\begin{array}{l}\text { Lung/ } \\
\text { thymus }\end{array}$ & PFS (9-mo) & NCT01563354 & Enrolling \\
\hline III (CASTOR) & $\begin{array}{l}\text { [177Lu-DOTA0,Tyr3]- } \\
\text { octreotate vs IFN }\end{array}$ & 60 & GI NET & PFS & NCT01860742 & $\begin{array}{l}\text { Belgium, } \\
\text { opening } \\
2015\end{array}$ \\
\hline II/III (REMINET) & $\begin{array}{l}\text { Lanreotide vs placebo } \\
\text { after SD/CR on } \\
\text { chemotherapy or } \\
\text { biotherapy }\end{array}$ & 118 & pNET & PFS (6-mo) & - & $\begin{array}{l}\text { Europe, } \\
\text { opening } \\
2015\end{array}$ \\
\hline
\end{tabular}

Abbreviations: CR, complete response; GI, gastrointestinal; IFN, interferon; NET, neuroendocrine tumor; PFS, progression-free survival; pNET, pancreatic neuroendocrine tumor; SD, stable disease.

bind to somatostatin receptors and are internalized into the tumor cells, where they can be used for diagnostic and therapeutic purposes ("theranostics"). Through targeting somatostatin receptors in NETs with radiolabeled somatostatin analogues, a tumoricidal radiation dose is delivered, thus causing a localized antitumor effect. ${ }^{42}$

Somatostatin peptides with higher receptor affinity are conjugated with radiometal-labeling chelators. DOTA is a chelator capable of encapsulating hard metals, such as gallium, yttrium, or lutetium. The first generation of PRRTs in the 1990s used ${ }^{111}$ In, a $\gamma$-emitter. ${ }^{43,44}$ Although these showed encouraging responses in terms of symptom relief, tumor shrinkage, and patient survival, they were also associated with significant bone marrow toxicity, including myelodysplastic syndrome and leukemia. The second generation of PRRTs used yttrium-90 ( $\left.{ }^{90} \mathrm{Y}\right)$-labeled DOTA $^{0}$, Tyr $^{3}$-octreotide, which has been evaluated in several phase I to II studies. ${ }^{45-49}{ }^{90} \mathrm{Y}$ is a pure $\beta$-emitter with a relatively long tissue penetration range $(12 \mathrm{~mm})$, which enables it to easily penetrate larger lesions. These studies reported modest response rates, ranging from $25 \%$ to $30 \%$. However, renal toxicity was noted to be a common a dose-limiting side effect of this treatment, and the administration of ${ }^{90} \mathrm{Y}$ PRRT required amino acid infusion for nephroprotection. Since 2000 lutetium-177 ( $\left.{ }^{177} \mathrm{Lu}\right)$ labeled DOTA $^{0}, \mathrm{Tyr}^{3}$-octreotate has been used for PRRT. ${ }^{177} \mathrm{Lu}$ is a medium-energy $\beta$-emitter with an approximate half-life of 6.7 days and a maximal tissue penetration of $2 \mathrm{~mm}$. Table 1 lists the affinity of somatostatin and radiopeptides to the somatostatin receptor subtypes.

In 2008, Kwekkeboom et $\mathrm{al}^{50}$ reported a retrospective analysis of 500 patients treated with $\left[{ }^{177} \mathrm{Lu}\right.$ DOTA $\left.^{0}, \mathrm{Tyr}^{3}\right]$-octreotate up to a cumulative dose of 750 to $800 \mathrm{mCi}(27.8-29.6 \mathrm{GBq})$, usually in 4 treatment cycles, with treatment intervals of 6 to 10 weeks. Complete and partial tumor remissions occurred in $2 \%$ and $28 \%$ of the patients, respectively, and minor tumor response (decrease in size $>25 \%$ and $<50 \%$, respectively) occurred in $16 \%$. Median time to progression was 40 months, and median OS from start of treatment was 46 months. Acute toxicities included nausea and vomiting, and subacute toxicities included grade $3 / 4$ hematologic toxicity (in $9.5 \%$ of patients $4-8$ weeks after $3.6 \%$ of administrations) and alopecia (62.0\%). Nine patients experienced serious delayed toxicities, including renal insufficiency $(n=2)$, liver toxicity $(n=3)$, and myelodysplastic syndrome $(n=4)$.

Although PRRT has been used for the treatment of metastatic somatostatin receptor-positive NETs in Europe since the 1990s, it is not approved by the FDA because of the lack of randomized data. The first phase III, randomized, multinational clinical trial of PRRT is now underway. The NETTER-1 study will compare ${ }^{177} \mathrm{Lu}$-DOTA ${ }^{0}, \mathrm{Tyr}^{3}$-octreotate to highdose octreotide LAR (60 mg monthly) in patients 
with inoperable, somatostatin receptor-positive metastatic midgut NETs who have experienced progressive disease on standard doses (20-30 mg every 3 to 4 weeks) of octreotide LAR (ClinicalTrials.gov identifier: NCT01578239). The accrual goal is 280 patients and the primary end point is progressionfree survival. Additionally, novel radiolabelled somatostatin antagonists are being developed for both imaging and treatment. ${ }^{51}$

\section{Future Directions}

Considerable advances have been made in the treatment NETs in the past decade. Although the use of somatostatin analogues for symptom control has been prevalent for decades, somatostatin analogues have recently been shown to also serve as antiproliferative agents. Given that somatostatin analogues have a favorable side effect profile, they are a reasonable option early in the disease course and may also serve as building blocks for combination therapies. Prospective clinical trials are also underway to evaluate radiolabeled somatostatin agonists and antagonists.

\section{References}

1. Lawrence B, Gustafsson BI, Chan A, et al. The epidemiology of gastroenteropancreatic neuroendocrine tumors. Endocrinol Metab Clin North Am 2011;40:1-18, vii.

2. Yao JC, Hassan M, Phan A, et al. One hundred years after "carcinoid": epidemiology of and prognostic factors for neuroendocrine tumors in 35,825 cases in the United States. J Clin Oncol 2008;26:3063-3072.

3. Garcia-Carbonero R, Capdevila J, Crespo-Herrero G, et al. Incidence, patterns of care and prognostic factors for outcome of gastroenteropancreatic neuroendocrine tumors (GEP-NETs): results from the National Cancer Registry of Spain (RGETNE). Ann Oncol 2010;21:1794-1803.

4. Mocellin S, Nitti D. Gastrointestinal carcinoid: epidemiological and survival evidence from a large population-based study $(n=25$ 531). Ann Oncol 2013;24:3040-3044.

5. Rindi G AR, Bosman FT, et al. Nomenclature and classification of neuroendocrine neoplasms of the digestive system. In: Bosman TF, Carneiro F, Hruban RH, Theise ND, eds. WHO Classification of Tumours of the Digestive System. 4th ed. Lyon, France: International Agency for Research on Cancer (IARC); 2010:13

6. Reisine T, Bell GI. Molecular biology of somatostatin receptors. Endocr Rev 1995;16:427-442.

7. Reichlin S. Somatostatin. N Engl J Med 1983;309:1495-1501

8. Larsson LI, Goltermann N, de Magistris L, et al. Somatostatin cell processes as pathways for paracrine secretion. Science 1979;205:1393-1395.

9. Nilsson O, Kolby L, Wangberg B, et al. Comparative studies on the expression of somatostatin receptor subtypes, outcome of octreotide scintigraphy and response to octreotide treatment in patients with carcinoid tumours. Br J Cancer 1998;77:632-637.

10. Lamberts SW, van der Lely AJ, de Herder WW, Hofland LJ. Octreotide. N Engl J Med 1996;334:246-254.

11. de Herder WW, Hofland LJ, van der Lely AJ, Lamberts SW. Somatostatin receptors in gastroentero-pancreatic neuroendocrine tumours. Endocr Relat Cancer 2003;10:451-458.
12. Fjallskog ML, Ludvigsen E, Stridsberg M, et al. Expression of somatostatin receptor subtypes 1 to 5 in tumor tissue and intratumoral vessels in malignant endocrine pancreatic tumors. Med Oncol 2003;20:59-67.

13. Modlin IM, Pavel M, Kidd M, Gustafsson BI. Review article: somatostatin analogues in the treatment of gastroenteropancreatic neuroendocrine (carcinoid) tumours. Aliment Pharmacol Ther 2010;31:169-188.

14. Brazeau P, Vale W, Burgus R, et al. Hypothalamic polypeptide that inhibits the secretion of immunoreactive pituitary growth hormone. Science 1973;179:77-79.

15. Reichlin S. Secretion of somatostatin and its physiologic function. J Lab Clin Med 1987;109:320-326.

16. Thulin L, Samnegard H, Tyden G, et al. Efficacy of somatostatin in a patient with carcinoid syndrome. Lancet 1978;2:43.

17. Guillemin R. Peptides in the brain: the new endocrinology of the neuron. Science 1978;202:390-402.

18. Oberg K. Future aspects of somatostatin-receptor-mediated therapy. Neuroendocrinology 2004;80(Suppl 1):57-61.

19. Kidd M, Drozdov I, Joseph R, et al. Differential cytotoxicity of novel somatostatin and dopamine chimeric compounds on bronchopulmonary and small intestinal neuroendocrine tumor cell lines. Cancer 2008;113:690-700.

20. Bruns C, Lewis I, Briner U, et al. SOM230: a novel somatostatin peptidomimetic with broad somatotropin release inhibiting factor (SRIF) receptor binding and a unique antisecretory profile. Eur J Endocrinol 2002;146:707-716.

21. Wild D, Schmitt JS, Ginj M, et al. DOTA-NOC, a high-affinity ligand of somatostatin receptor subtypes 2, 3 and 5 for labelling with various radiometals. Eur J Nucl Med Mol Imaging 2003;30:1338-1347.

22. Reubi JC, Schar JC, Waser B, et al. Affinity profiles for human somatostatin receptor subtypes SST1-SST5 of somatostatin radiotracers selected for scintigraphic and radiotherapeutic use. Eur J Nucl Med 2000;27:273-282.

23. Rubin J, Ajani J, Schirmer W, et al. Octreotide acetate long-acting formulation versus open-label subcutaneous octreotide acetate in malignant carcinoid syndrome. J Clin Oncol 1999;17:600-606.

24. Bajetta E, Procopio G, Catena L, et al. Lanreotide autogel every 6 weeks compared with Lanreotide microparticles every 3 weeks in patients with well differentiated neuroendocrine tumors: a phase III study. Cancer 2006;107:2474-2481.

25. Ruszniewski P, Ish-Shalom S, Wymenga M, et al. Rapid and sustained relief from the symptoms of carcinoid syndrome: results from an open 6-month study of the 28-day prolonged-release formulation of lanreotide. Neuroendocrinology 2004;80:244-251.

26. Khan MS, El-Khouly F, Davies $\mathrm{P}$, et al. Long-term results of treatment of malignant carcinoid syndrome with prolonged release Lanreotide (Somatuline Autogel). Aliment Pharmacol Ther 2011;34:235-242.

27. O'Toole D, Ducreux M, Bommelaer G, et al. Treatment of carcinoid syndrome: a prospective crossover evaluation of lanreotide versus octreotide in terms of efficacy, patient acceptability, and tolerance. Cancer 2000;88:770-776

28. Vinik A, Wolin E, Audry H, Gomez-Panzani E. ELECT: a phase 3 study of efficacy and safety of lanreotide autoge/depot (LAN) treatment for carcinoid syndrome in patient with neuroendocrine tuors (NETs) [abstract]. J Clin Oncol 2014;32(Suppl 3):Abstract 268.

29. Schmid HA, Schoeffter P. Functional activity of the multiligand analog SOM230 at human recombinant somatostatin receptor subtypes supports its usefulness in neuroendocrine tumors. Neuroendocrinology 2004;80(Suppl 1):47-50.

30. Wolin EM, Jarzab B, Eriksson B, et al. A multicenter, randomized, blinded, phase III study of pasireotide LAR versus octreotide LAR in patients with metastatic neuroendocrine tumors (NET) with disease-related symptoms inadequately controlled by somatostatin analogs [abstract]. J Clin Oncol 2013;31(Suppl):Abstract 4031.

31. Massimino K, Harrskog O, Pommier S, Pommier R. Octreotide LAR and bolus octreotide are insufficient for preventing intraoperative complications in carcinoid patients. J Surg Oncol 2013;107:842-846.

32. Kulke $M H$, Shah $M H$, Benson $A B$, et al. NCCN Clinical Practice Guidelines in Oncology for Neuroendocrine Tumors. Version 1.2015. Available at NCCN.org. Accessed December 22, 2014.

33. Boyd AE, DeFord LL, Mares JE, et al. Improving the success rate of gluteal intramuscular injections. Pancreas 2013;42:878-882.

34. Strosberg JR, Benson AB, Huynh L, et al. Clinical benefits of abovestandard dose of octreotide LAR in patients with neuroendocrine tumors for control of carcinoid syndrome symptoms: a multicenter retrospective chart review study. Oncologist 2014;19:930-936. 
35. Shen C, Shih YC, Xu Y, Yao JC. Octreotide long-acting repeatable use among elderly patients with carcinoid syndrome and survival outcomes: a population-based analysis. Cancer 2014;120:2039-2049.

36. Schally AV. Oncological applications of somatostatin analogues. Cancer Res 1988;48(24 Pt 1):6977-6985.

37. Susini C, Buscail L. Rationale for the use of somatostatin analogs as antitumor agents. Ann Oncol 2006;17:1733-1742.

38. Lawnicka H, Stepien H, Wyczolkowska J, et al. Effect of somatostatin and octreotide on proliferation and vascular endothelial growth factor secretion from murine endothelial cell line (HECa10) culture. Biochem Biophys Res Commun 2000;268:567-571.

39. Rinke A, Muller HH, Schade-Brittinger C, et al. Placebo-controlled, double-blind, prospective, randomized study on the effect of octreotide LAR in the control of tumor growth in patients with metastatic neuroendocrine midgut tumors: a report from the PROMID Study Group. J Clin Oncol 2009;27:4656-4663.

40. Caplin M, Ruszniewski P, Pavel M, et al. Progression-free survival (PFS) with lanreotide autogel/depot (LAN) in enteropancreatic NETs patients: the CLARINET extension study [abstract]. J Clin Oncol 2014;32(Suppl):Abstract 4107

41. Oberg K, Kvols L, Caplin M, et al. Consensus report on the use of somatostatin analogs for the management of neuroendocrine tumors of the gastroenteropancreatic system. Ann Oncol 2004;15:966-973.

42. Heppeler A, Froidevaux S, Eberle AN, Maecke HR. Receptor targeting for tumor localisation and therapy with radiopeptides. Curr Med Chem 2000;7:971-994.
43. Valkema R, De Jong M, Bakker WH, et al. Phase I study of peptide receptor radionuclide therapy with [In-DTPA] octreotide: the Rotterdam experience. Semin Nucl Med 2002;32:110-122.

44. De Jong $M$, Valkema $\mathrm{R}$, Jamar $\mathrm{F}$, et al. Somatostatin receptor-targeted radionuclide therapy of tumors: preclinical and clinical findings. Semin Nucl Med 2002;32:133-140.

45. Waldherr $C$, Pless $M$, Maecke $H R$, et al. The clinical value of [90Y-DOTA]-D-Phe1-Tyr3-octreotide (90Y-DOTATOC) in the treatment of neuroendocrine tumours: a clinical phase II study. Ann Oncol 2001;12:941-945.

46. Waldherr C, Pless M, Maecke HR, et al. Tumor response and clinical benefit in neuroendocrine tumors after 7.4 GBq (90)Y-DOTATOC. J Nucl Med 2002;43:610-616

47. Paganelli G, Bodei L, Handkiewicz Junak D, et al. 90Y-DOTA-D-Phe1Try3-octreotide in therapy of neuroendocrine malignancies. Biopolymers 2002;66:393-398.

48. Bodei L, Cremonesi M, Zoboli S, et al. Receptor-mediated radionuclide therapy with 90Y-DOTATOC in association with amino acid infusion: a phase I study. Eur J Nucl Med Mol Imaging 2003;30:207-216.

49. Bushnell D, O'Dorisio T, Menda Y, et al. Evaluating the clinical effectiveness of 90Y-SMT 487 in patients with neuroendocrine tumors. J Nucl Med 2003;44:1556-1560.

50. Kwekkeboom DJ, de Herder WW, Kam BL, et al. Treatment with the radiolabeled somatostatin analog [177 Lu-DOTA 0,Tyr3]octreotate: toxicity, efficacy, and survival. J Clin Oncol 2008;26:2124-2130.

51. Wild D, Fani M, Fischer R, et al. Comparison of somatostatin receptor agonist and antagonist for peptide receptor radionuclide therapy: a pilot study. J Nulc Med 2014;55:1248-1252.

\section{Instructions for Completion}

To participate in this journal CE activity: 1) review the learning objectives and author disclosures; 2 ) study the education content; 3 ) take the posttest with a $66 \%$ minimum passing score and complete the evaluation at http://education.nccn.org/ node/59437; and 4) view/print certificate. After reading the article, you should be able to answer the following multiple- choice questions. Credit cannot be obtained for tests completed on paper. You must be a registered user on NCCN.org. If you are not registered on NCCN.org, click on "New Member? Sign up here" link on the left hand side of the Web site to register. Only one answer is correct for each question. Once you successfully answer all posttest questions you will be able to view and/or print your certificate. Software requirements: Internet

\section{Posttest Questions}

1. Which of the following nonsurgical options may be used in the management of unresectable metastatic neuroendocrine tumors?
a. Cytotoxic chemotherapy
b. Somatostatin analogues
c. Liver-directed therapies
d. Systemic therapy with molecularly targeted agents
e. All of the above
f. None of the above

2. True or False: Hyperglycemia, diarrhea, and steatorrhea are possible side effects of somatostatin analogues.

3. The suggested starting dose of octreotide acetate ranges from:

a. 100 to $200 \mathrm{mcg} / \mathrm{d}$ in 2 to 4 divided doses without a routine test dose

b. 100 to $600 \mathrm{mcg} / \mathrm{d}$ in 2 to 4 divided doses without a routine test dose

c. 100 to $600 \mathrm{mcg} / \mathrm{d}$ in 2 to 4 divided doses with a routine test dose

d. 200 to $400 \mathrm{mcg} / \mathrm{d}$ in 2 divided doses 